\title{
Experimental Study on The Development of Depth-Averaged Flow in a Rectangular Continuous Bends
}

\author{
Nobuyuki Tamai,Associate Professor \\ Dept.of Civil Eng. \\ University of Tokyo. \\ and \\ O Ali A. Mohamed, Graduate Student \\ University of Tokyo.
}

\section{INTRODUCTION.}

Strong secondary currents and scour holes and deposit induced by secodary currents have been important research themes in river engineering. In rivers we have continuous meandering channels. However, previous analysis lay their stress on one single bend ${ }^{1}$. In this experiment 10 consecutive bends are utilized to measure the velocity field, water depth, and the flow direction. The test series was designed to give a width-depth ratio smaller than 10 with Reynolds number, $R_{n}$, bigger than 10000 and Froude number, $\mathrm{F}_{\mathrm{r}}$, smaller than 0.6 .This series of experiment was performed as an extention of the previous experiment ${ }^{2}$ carried out in our laboratory in order to obtain measured results for enough high Reynolds number. As the first stage of a research program a rectangular,fixed-bed model is utilized.

\section{EXPERIMENTAL PROCEDURES AND DISCUSSION.}

The experiments were carried out in a flume that has ten $90^{\circ}$ consecutive bends(Fig.l). The flume has also $45^{\circ}$ bends at the head and the tail of these consecutive bends and also it has a straight reach to connect with the measuring tank.For this simplified model (Fig. (2)), the geometry of the channel are defined as follows:the central angle of the bend is $90^{\circ}$, centerline radius $r_{\mathrm{C}}=60 \mathrm{~cm}$, the tangent length $\mathrm{T}=30 \mathrm{~cm}$, the width of the flume $\mathrm{B}_{\mathrm{O}}=30 \mathrm{~cm}$. and the cross section is rectangular. The planimetric geometry of the flume is close to the sine-generated curve (Fig.2). In all the experiments the bed of the flume had a slope of $1 / 1000$ along the longitudinal direction and it was kept horizontal through transverse direction. The measurement was carried out for only the middle part of the flume, that is, the 4 th, 5 th, 6 th and 7 th bends,

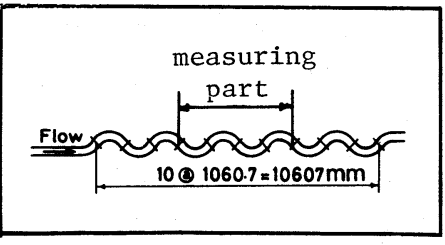

Fig.1 Experimental Flume.

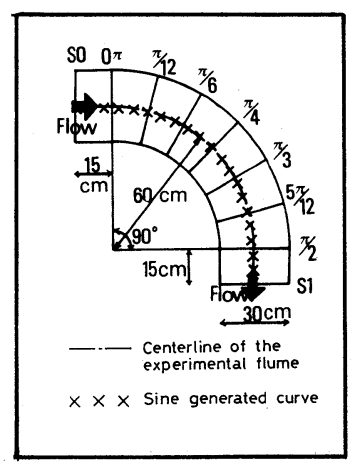

Fig.2 Definition Sketch. 
since we observed almost the identical behavior of flow for the same location in the phase of a bend ${ }^{2}$. The location of the four test bends is shown in Fig. (1).

For each unit bend, the measurements were performed in cross-section at every $\pi / 12-r a d$, The section in a circular part were named by their angle in radians from the bend entrance and $\mathrm{S}_{\mathrm{o}}$ corresponds to a midpoint of the tangent reach (see Fig.2). In the transverse direction seven subareas are set for measurements and 9 observation points with the interval of $0.5 \mathrm{~cm}$ are placed along a vertical line in each sub-area.

The surface water profile was measured with seven static pressure tubes connected to a manometer. The direction of the flow at different points in the stream was measured tuft visualization.The diameter of the propeller of a current-meter is $3 \mathrm{~mm}$.

From the experimental results plotted, we confirmed that the flow field at the same phase in bends is the same.Hereinafter, the average values at the same phase among four bends are presented as experimental results. The variation of the water surface profile is shown in Fig. (8). In this part just observed characteristics are explained briefly.Atisection $\mathrm{S}_{\mathrm{o}}$, the middle section of the straight reach between two unit bends, the transverse water surface gradiant is exactly horizontal and the water depth at this section is equal to the representative water depth $\mathrm{H}_{\mathrm{O}}$, which is equal to the average of all the water depths measured through one unit bend.From Fig.8, we can see that, the transverse watersurface gradient increases up to the maximum at the section $\pi / 6$ which is one third of the process of total change in the flow direction. The transverse water surface gradient keeps about the same magnitude up to the section $5 \pi / 12$ and then sharply reduces to zero at section $\mathrm{S}_{1}$.

The vertical velocity distribution for longitudinal flow component $U_{S}$ is shown in Fig.3.From this Fig. 3 we can clearly see that there is an unusual velocity distribution in which the maximum velocity appears in the middle of the depth or near the bottom. This barrel-type velocity distribution shown by a solid line in Fig. 3 seems ito be inherent to the transitional charact

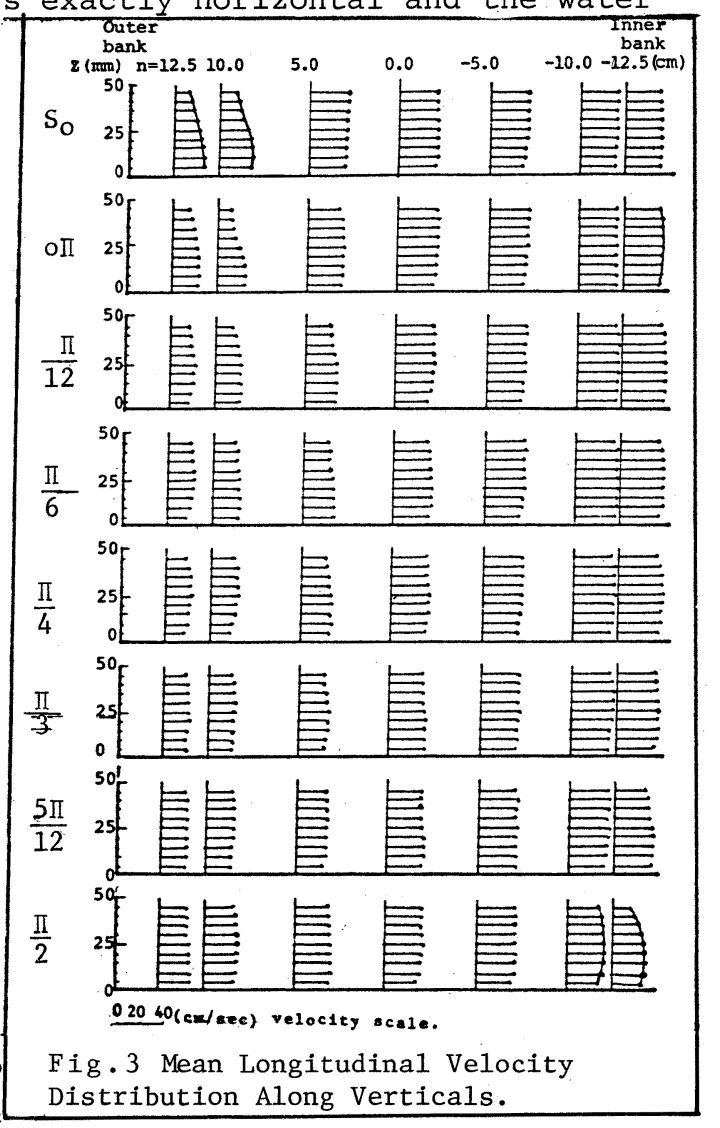


teristics of the flow in continuous bends. From Rige 3 we thave obtained Fig. 4 which shows the horizontal distribution of depth-averaged longitudinal velocity $U_{S}$. It has been observed that the depth-averaged velocity near the inner bank is accelerated while the velocity near the outer bank is decelerated near the entrance of a bend. The trend lasts up to the section $\pi / 4$ where the maximum transverse gradient appears. After that, the velocity difference along the outer and the inner banks begins to decrease toward the section $s_{1}$, the entrance to the next unit bend.
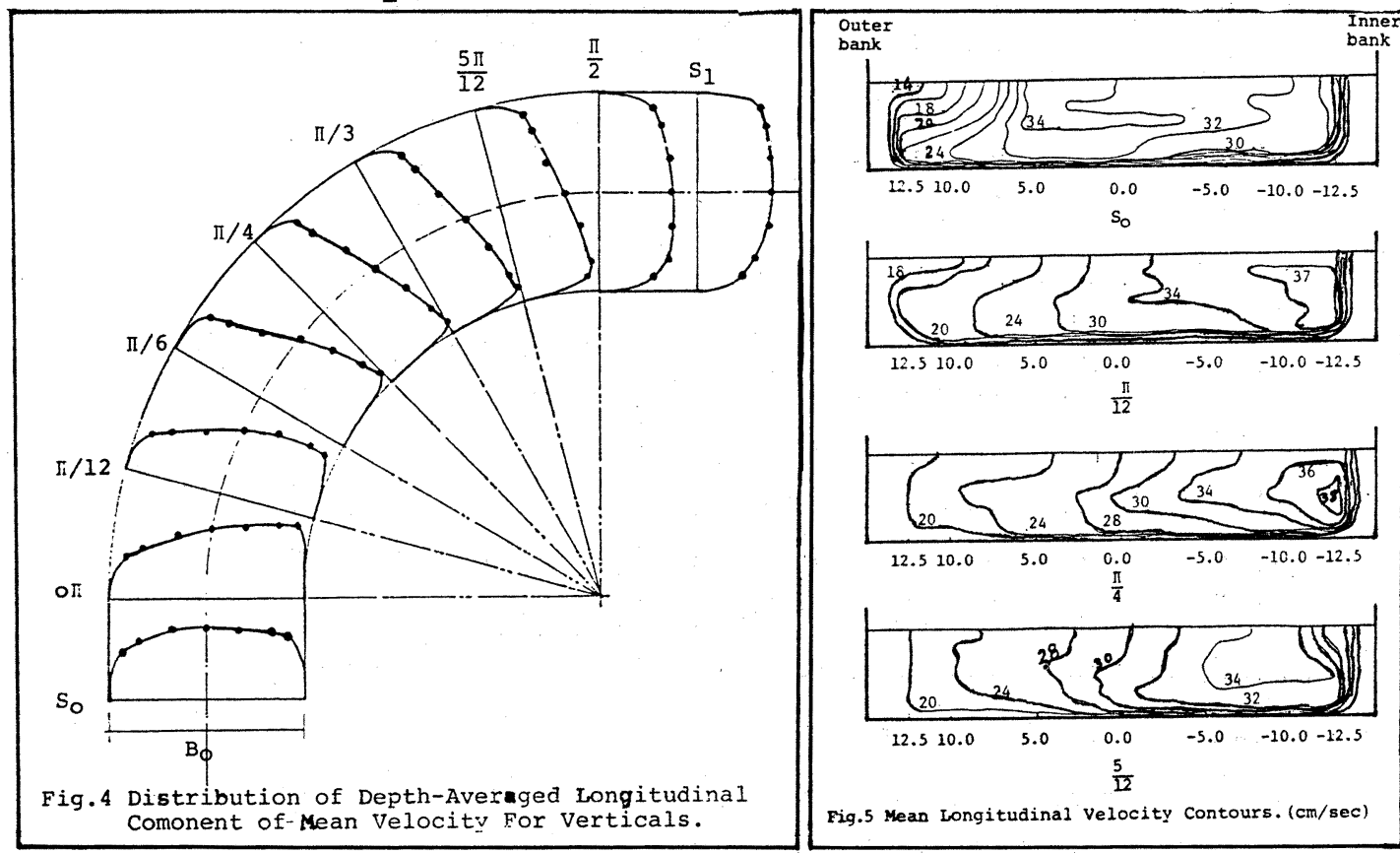

Also, to obtain the data for velocity contours such as those in Fig.5 the same data in Fig. 3 are utilized.From Fig. 5 we can see that convergence of the flowing mass takes place toward the inner bank up to section $\pi / 4$ and after that the opposite situation prevails.

Fig. 6 shows the distribution of radial mean velocity component $U_{n}$ in which $U_{n}=U_{S} \tan \delta$ where $\delta$ is the angle between the flow direction and the tangent of a sine-generated curve.

From Fig. 6 we can see clearly that the net radial transport towerd the inner bank at the centerline is positive up to the cross section $\pi / 6$ and from section $5 \pi / 12$ up to $\pi / 2$ this amoxant is negative.Based on Fig. 6 we constructed Fig.7, which shows the variation of secondary flow pattern along the bends. The cross section $S_{O}$ shows the observed result at the entrance of a unit bend and the direction of the secondary circulation in this case is opposite from the usual sense, because near the surface, secondary flow goes from the outer bank to the inner bank. At section $1 / 12$, as the flow goes to downstream, a new secandary circulation generated develops near the bottom, which has the opposite circulating direction compare- 

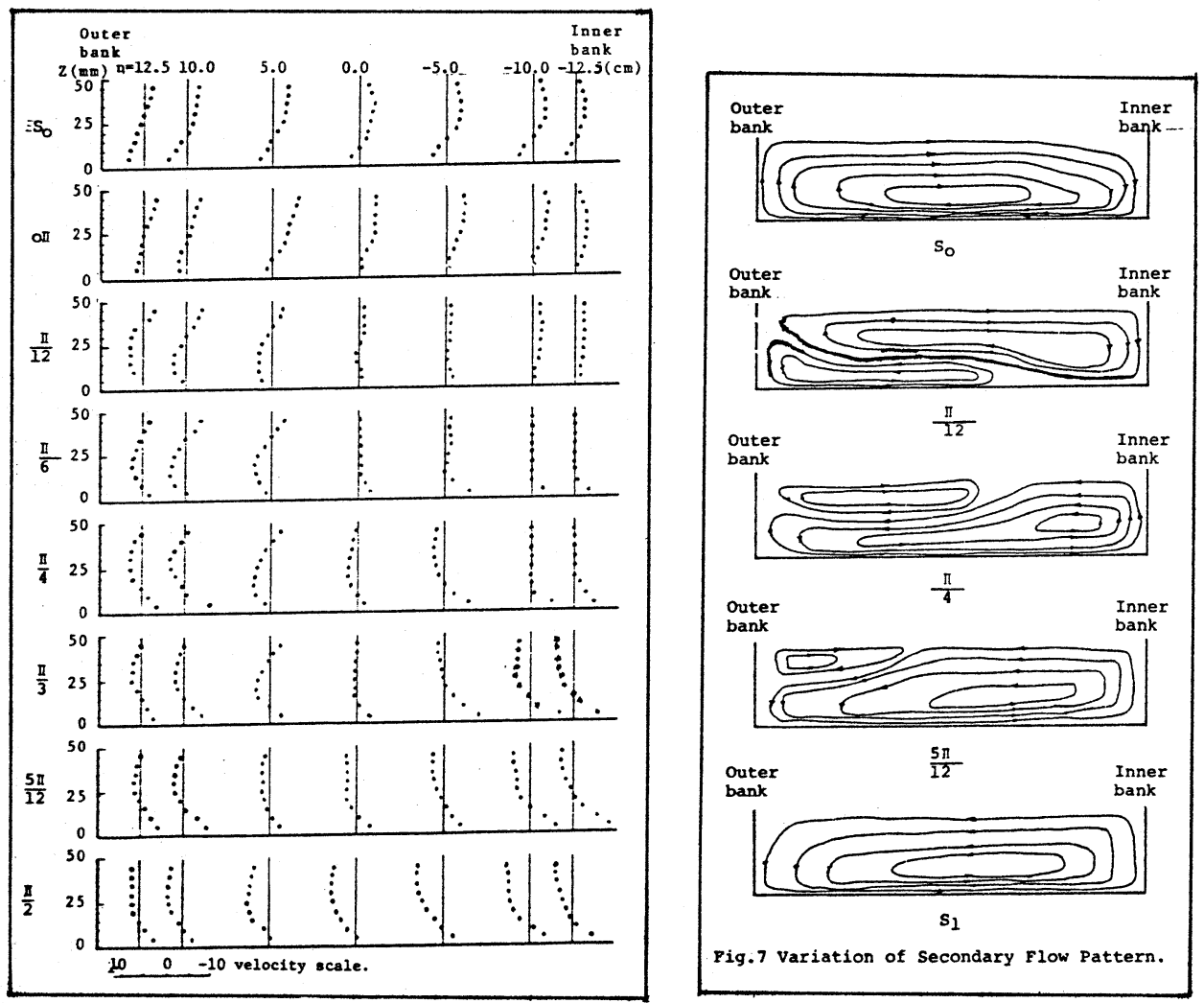

Fig. 6 Distribution of Radial

Mean Velocity Component.

ed with a preceding one.At section $\pi / 12$ and $\pi / 4$ two oppositely circulating secondary currents coexist sharing a comparable area in the section. Then, in the exit region $s_{1}$ a new secandary current finally occupies the whole section. Between sections $5 \pi / 12$ and $S_{1}$ we can observe a fully developed secondary current but this fully developed region does not exist continuously toward the next bend for the case of continuous bends, like the present study.T he growth of the spiral in a bend is strongly affected by the residual spiral from a preceding bend, while the decay of the spiral from the preceding bend is accelerated by the growth of a new spiral.

By comparing these experimental results with previous experimental results ${ }^{2}$ for the surface water profile, the longitudnal velocity, the radial velocity, the depth-averaged flow and the variation of secondary flow pattern, there is no appreciable difference.Also,there is no separation of the flow throughout the experiments.Therefore, it is said that experimental results reported in this paper demonstrate the general flow field in bends under the wide range of hydraulic conditions, namely, the widthdepth ratio larger than 6 and the Reynolds number larger than 5500 . 

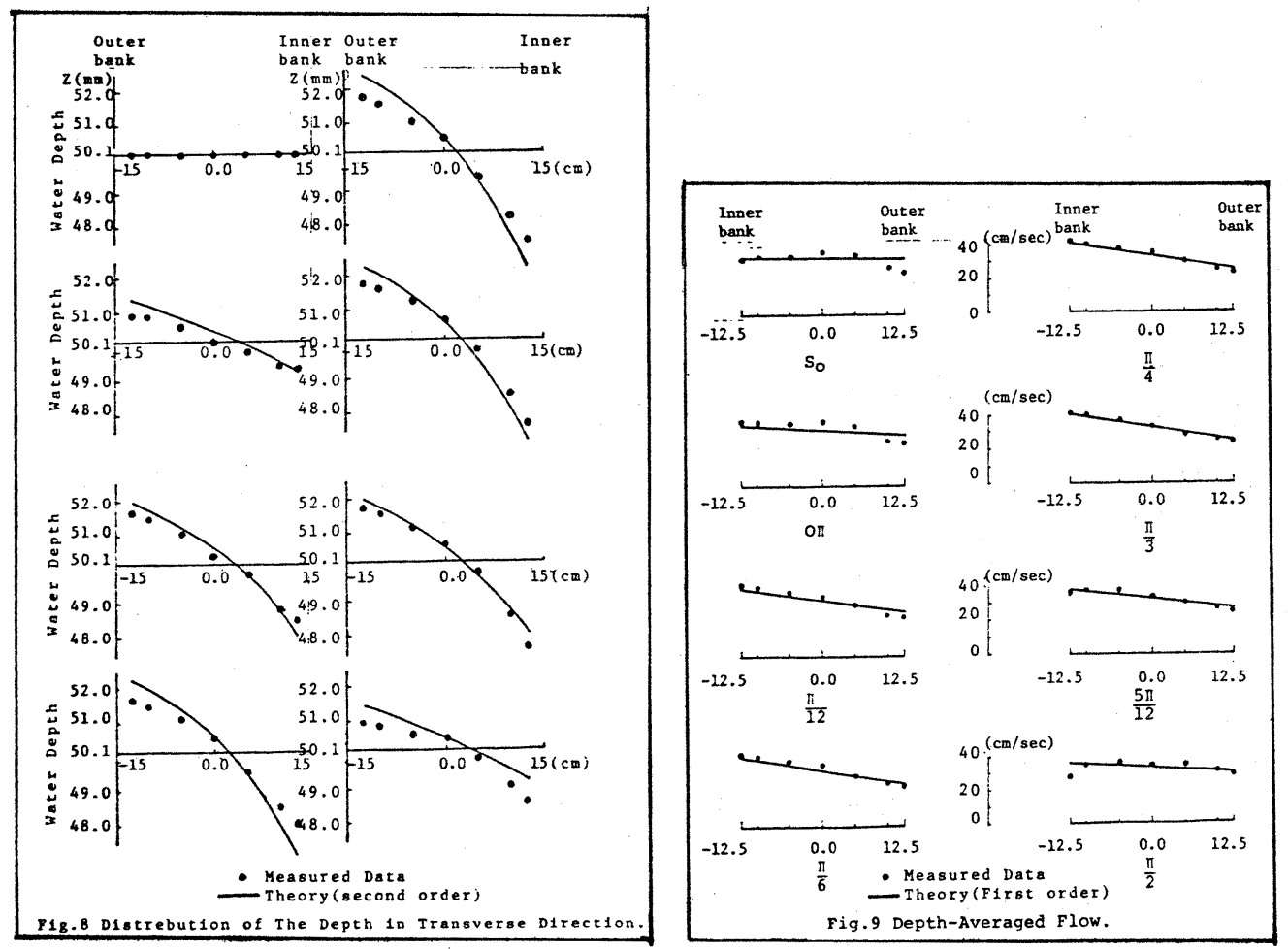

\section{COMPARISON WITH THEORETICAL VALUES.}

The experimental results are compared with theoretical values ${ }^{5)}$ for the second order theory in case of water surface profile and the first order theory in case of longitudinal velocity. In the previous experiment described in the paper ${ }^{2}$, the Reynolds number, $R_{n}$, was about 5500 . Because the velocity in the zone near the outer bank is lower than the sectional average as shown in Fig.4, the same kind of experiment with higher Reynolds number was planned to obtain a complete picture of a flow in a meandering channel. In the present experiment, the minimum value of the $R_{n}$ is around 8000 in the zone near the outer bank and the result is suitable for comparison with the theory derived under the condition of fully developed turbulent flow.

Table(1) Comparison of Hydraulic Conditions.

\begin{tabular}{|c|c|c|c|c|c|c|}
\hline & $\begin{array}{c}\text { mean water } \\
\text { depth } \\
\mathrm{H}_{\mathrm{O}} \mathrm{cm} .\end{array}$ & $\begin{array}{c}\text { width- } \\
\text { depth } \\
\text { ratio }\end{array}$ & $\begin{array}{c}\text { mean } \\
\text { velocity } \\
\mathrm{V}_{\mathrm{O}} \text { (cm/sec) }\end{array}$ & $\begin{array}{c}\text { friction } \\
\text { factor } \\
\mathrm{f}\end{array}$ & $\mathrm{F}_{\mathrm{r}}$ & $\mathrm{R}_{\mathrm{n}}$ \\
\hline $\begin{array}{c}\text { Experiment in } \\
\text { Eke paper (2) }\end{array}$ & 2.93 & 10.0 & 22.30 & 0.0115 & 0.42 & 5500 \\
\hline $\begin{array}{c}\text { Present } \\
\text { study }\end{array}$ & 5.01 & 6.0 & 32.77 & 0.00916 & 0.47 & 13500 \\
\hline
\end{tabular}


The theory deals with the flow in a channel whose centerline follows a sine generated curve.At first we want to approximate our flume to an appropriate sine generated curve.By calculating $\theta_{0}$ the maximum angle that the centerline of the channel intersects with mean downpath direction in the sine-generated curve,it is found equal to $44.67^{\circ}$. The experimental results have been calculated considering that the centerline of the flume is a sine-generated curve.

For the first comparison, as shown in Fig.8, the theoretical values are not in very good agreement with the experiment for the water depth especially in the region close to the side walls.Comparison between the experimental results for the depth-averaged flow velocity and the thec retical results, shows fairly good agreement as shown in Fig.9.

\section{CONCLUSIONS .}

The following conclusions are obtained through the present study: l-Water depth,longitudinal velocity and transverse velocity observed in continuous bends show repeated occurrence of nearly the identical values at the same phase of each bend.This means that the flow in continuous bends reaches its dynamical equilibrium within one unit bend.

2-The effect of a residuai secondary current of a preceding bend prevails in the upper half reach of a next bend.

3-There is no appreciable change in flow patterns from macroscopic point of view between the experiment of width-depth ratio $\mathrm{B} / \mathrm{H}=10$ and the Reynolds number, $R_{n}=5500$, and $B / H=6$ and $R_{n}=13500$.

4-The first order theory gives fairly good agreement with the observed depth-averaged flow velocity but even the second order theory for the water depth is not sufficiently good to expiain the variation along the bend.

\section{REFERENCES .}

1) Rozovskii,I.L."Flow of Water in Bends of Open Channels,"Israel program for scientific translation,1961.

2) Tamai,N.,K.Ikeuchi and A.Yamazaki,"Experimental analysis of the open channel flow in continuous bends"Proc.JSCE, No.331,March.1983 (in print)

3) Langbein, W.B.and L.B.Leopold, "River meanders-theory of minimum variancë U.S.G.S.Prof.paper 422-H,1966.

4) Siebert,W. and W.Gotz,"A study on the deformation of secondary flow in models of rectangular meandering channels,Proc.16th.Congress, IAHR, vol. 2 ,pp.141-149,1975.

5) Ikeuchi,K. and N.Tamai,"Evolution of the depth-averaged flow field in meandering channels", Proc.JSCE, (to be published). 